\title{
An Implementation Architecture of Carbon Emissions for High-Performance Machine-Tool Product Service System
}

\author{
Fuqiang Zhang ${ }^{\mathrm{a}}$, Jingjing $\mathrm{Li}^{\mathrm{b}}$, Zeyu Zhang ${ }^{\mathrm{c}}$ \\ Key Laboratory of Road Construction Technology and Equipment of MOE, Chang'an University, \\ Xi'an 710064, China \\ afqzhang2013@aliyun.com, b1577321870@qq.com, 'czhangzeyu@chd.edu.cn
}

Keywords: industrial product service system, carbon footprint, implementation architecture.

\begin{abstract}
Low-carbon manufacturing is a sustainable manufacturing model that takes into account both resource consumption and carbon emissions. The goal is to achieve low resource consumption, low emissions and low pollution during the production, manufacture and use of products. Taking the high-performance machine-tool product service system as the research object, an implementation architecture of evaluating its carbon emissions was proposed. The concepts of machine-tool product service system and carbon footprint were introduced. Then, three key enabling technologies were presented. It is expected that the study can provide a useful reference for achieving low carbon transition in manufacturing.
\end{abstract}

\section{Introduction}

As the problem of industrial pollution and resources shortage, it has reached consensus of all countries around the world on developing and promoting low-carbon manufacturing technology vigorously. Low-carbon manufacturing is a kind of sustainable manufacturing mode comprehensively considering the resources consumption and carbon emissions of product life cycle, and its essence is to improve resource utilization efficiency and create clean energy structure [1, 2]. In recent years, manufacturing enterprises are divided into two kinds of different and independent companies: manufacturing sectors and service sectors. In particular, the manufacturing sectors are responsible for product fabrication; while the service sectors are responsible for product using and recycling. Under this circumstance, an industrial product services are being widely used as new philosophy to address the increasing needs of environmental protection. Different from traditional after-sale services or after-services mode, industrial product venders/manufacturers are required to sell, provide, and maintain intangible product services together with the industrial products to enterprise users. In this paper, the carbon emissions for high-performance machine-tool product service system were investigated. It can be predicted that this research could provide a valuable reference for industrial product service providers.

\section{Clarifying the concepts}

\subsection{High-performance machine-tool product service system}

Industrial product service system (iPSS) can be defined as a systematic package in which intangible services are attached to tangible products to finish various industrial activities in the whole product life-cycle [3]. Depending on the active service-driven work of product venders/manufacturers or the third party service providers, and the auxiliary participation of iPSS acceptors/users, here, working capabilities of the tangible products as intangible services are sold, enabled, and maintained. At the same time, environmental issues can be assured through such a package. As shown in Fig.1, all kinds of raw material and energy sources were used as the inputs; manufacturing sector was responsible for the design and fabrication of industrial products; while service sector was responsible for the using, maintenance and recovery by the means of industrial product service. It must point out that a great deal of industrial waste has discharged into the environment among its fabrication and service phase. 


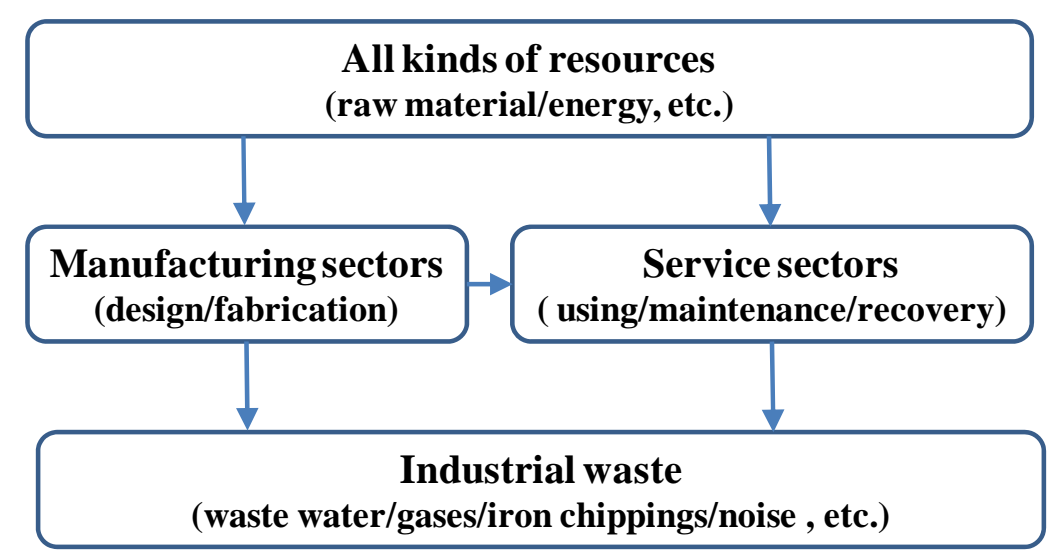

Fig.1 Inputs and outputs of machine-tool product service system based on carbon emissions

\subsubsection{Fabrication phase}

According to the design drawing, various raw material was fabricated into a high-performance machine-tool product. In this phase, environmental pollution and energy consumption could be analyzed since the selection of raw materials, planning of process and assembly could be reached to an optimal level to solve environmental pollution problem and reduce the industrial waste. The design/manufacturing/assembly was considered and the detailed contents were shown as follows.

- Design. It plays an important role in fabrication phase since different raw material and design models may lead to the different function and performance of finished products. It must point out that the raw material of low-energy consumption, less pollution, low cost and prone processing were selected firstly. Besides, an effective product structure could provide a base for machine and assembly of industrial product.

- Machine. According to above design drawing and process planning, supplied raw materials and energy resources were transmitted into an effective part of industrial product trough different machine tools and heat-treatment equipment leaving various industrial waste, such as noise, waste water, gas and solid waste. All this industrial waste can bring the environmental pollution problem.

- Assembly. Based on the inter-machined parts and outsourced parts, an effective industrial product could be assembled according to a series of assembly planning. An effective assembly planning could reduce the resources cost and enhance the production capacity since the assembly sequence could reduce the assembly time.

\subsubsection{Service phase}

In the service phase, industrial product could be used to complete all kinds of machining tasks in the workshop. In general, the parts with complex structure and high process requirement had to be machined on high-performance machine-tool product.

- Using and maintenance. Environmental pollution and energy consumption should be evaluated firstly, which were used to identify the effective process planning. For example, the selection of cutting parameters plays an important role in the life of cutting tools. In addition, different kinds of cutting tools could be used to cutting different materials.

- Recovery and remanufactured. In order to reduce the cost, some important parts of the older industrial product could be selected and re-manufactured. In this case, the environmental pollution and resources consumption could be reduced. In order to increase the recovery rate, the easy disassembly could be considered in the fabrication phase.

\subsection{Carbon footprint}

As an important tool of evaluating the carbon emission of industrial activity, carbon footprint has received wide attention from academia and industry [4]. From the perspective of product life cycle, it reveals the carbon emissions of different elements. Generally speaking, it is used to calculate the direct and indirect emissions of various greenhouse gases in the whole life cycle or some activities. Its goal is to explore a reasonable and effective way to reduce greenhouse gas emissions to provide a scientific basis. At present, there are three kinds of methods to evaluate and calculate the carbon emission of industrial activities. They are process-based life assessment (Process-based LCA), inputs-outputs life cycle assessment (EIO LCA), and hybrid life cycle assessment (hybrid LCA). In 
recent years, government and related departments adopted carbon footprint as the evaluation standards of industrial product and service as as to provide a decision base for determining the emission-reduced solution.

In general, the carbon footprint includes the direct and indirect gas emission of industrial product or service from the perspective of a life cycle. The direct emission is generated by the product or service, which refers to the production, transportation, sales and other processes of workpiece, raw materials, auxiliary materials (cutting fluid, lubrication fluid, etc.). The indirect emission is generated by the consumption of power and energy. According to the above description, the model of carbon footprint can be described as:

$$
\begin{aligned}
& G=G_{d}+G_{m}+G_{a}+G_{u}+G_{r} \\
& G^{i}=G^{i} \text { direct }+G^{i} \text { indirect }
\end{aligned}
$$

Where, $G_{d}$ represents the design of industrial products; $G_{m}$ represents the machining of industrial products; $G_{a}$ represents the assembly of industrial products; $G_{u}$ represents the service of industrial products; $G_{r}$ represents the recovery of industrial products. $G_{i}$ represents some phase in a life cycle. $G^{i}$ direct and $G^{i}$ indirect respectively represent the direct carbon emission by consuming the raw materials and indirect carbon emission by consuming the energy resources.

\section{Implementation architecture}

Under the background of the severe environment, the reducing of carbon emission of industrial product service system has been a new requirement and new challenges faced by enterprises. Taking the high-performance machine-tool product service system as the research object, the authors proposed an implementation architecture of carbon emissions as shown in Fig.2.

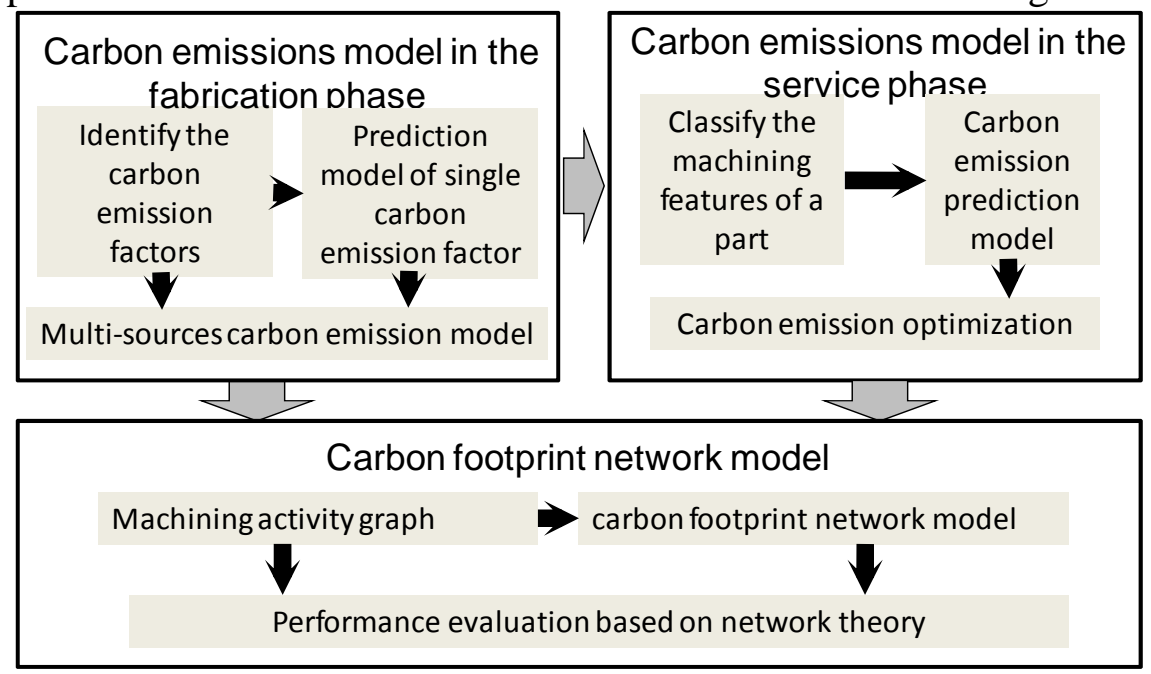

Fig.2 A carbon emissions architecture for implementing high-performance machine-tool product service system

\section{Key enabling technologies}

\subsection{Carbon emissions model in the fabrication phase of industrial products}

In this section, the inputss are all kinds of resources and energy, and outputss are the industrial waste and products with different functions. Carbon emissions include the preparation of raw materials, and maching/assembly of machine tool. The total amount of direct material consumption and indirect energy consumption of supporting parts, spindles, transmission gears, transmission screws, and tool changing devices, can be considered as the carbon emission of the machine tools [5].

- Identify and describe the carbon emission factors based on inputs-outputs analysis. Qualitative analysis can be used to identify the factors that influence carbon emissions, which are divided into direct energy consumption factors and indirect energy consumption factors. Based on human, machine and environment characteristics, the key factors (such as spindles, cutting tools, cutting fluid, etc.) can be extracted. 
- Prediction model of single carbon emission factor in the whole life cycle. According to the identified key factors, carbon emissions of the whole life cycle can be estimated from demand research, product design, raw materials preparation, manufacturing, assembly, packaging and transportation, operation, maintenance, disposal and recycling.

- Multi-sources carbon emission model under direct energy constraint. Based on the single factor carbon emission model, a multi-sources carbon emission model with direct energy consumption constraints can be established. Taking the total carbon emission as the optimization objective, an integrated prediction model was established by using modular combination theory.

\subsection{Carbon emissions model in the service phase of industrial products}

In this section, the inputs are machine tools and all kinds of resources/ energy; the outputs are different processing services to meet customer requirements. It must be noted that the type and quantity of carbon emissions in different running state are changeable, such as carbon emission mainly comes from power consumption under no-loading condition. Therefore, it mainly depends on the real-time outputs of various carbon emission sources under different working conditions.

- Classify and describe the machining features of parts. According to the typical machining features (such as plane, slot, and the outer circle), the set theory can be used to describe the structure characteristics of parts; relation algebra can be used to describe the correlations among machining features of parts.

- Prediction model of carbon emission under indirect energy consumption constraint. According to the working conditions of the machine tool, a neural network model was built to predict the carbon emission under the indirect energy consumption constrained by different process parameters (workpiece material, cutting tool type, machining parameters, cutting fluid, etc.).

- Carbon emission optimization of machine tool parameters. According to the above indirect energy consumption prediction model, an intelligent algorithm was used to optimize all kinds of process parameters, aiming to achieve higher efficiency and lower carbon emissions of machine tools.

\subsection{Carbon footprint network model for service-oriented machining}

Industrial product service system is a multi-level discrete and nonlinear complex dynamic system. Its inputs are the various energy and materials; outputss are the products or services with various wastes. Therefore, carbon footprint network model for service-oriented machining includes the material flow, energy flow and waste flow.

- Machining activity based on extended activity graph model. Using extended activity diagram, the workflow is viewed as a directed graph composed of nodes and connected arcs. Nodes represent activities (such as machining characteristics of rough machining), while the connecting arcs represent the carbon flow between the activities. The model can not only represent the physical attributes (resources, time, etc.) of activities, but also describe the relationships among processing activities.

Carbon emission driven carbon footprint network model. Based on the activity diagram model mentioned above, the machining elements and machining features are mapped into network nodes; the location/evolution relation between machining features, and the processing relation between machining feature and processing elements are mapped into the edges of the network; the carbon emissions among nodes are mapped into network edge weights.

- Complexity analysis and effectiveness evaluation based on network theory. According to the carbon footprint network model, some statistical indexes such as degree distribution, intermediate distribution, aggregation coefficient and shortest path are used to evaluate the small world and scale-free structure of the network. The network performance characteristics are evaluated by defining activity, sensitivity, and energy dissipation intensity.

\section{Conclusion}

Service-oriented machining powered with industrial product service systems in workshop level is quite a new research topic. Low-carbon manufacturing is a sustainable manufacturing model that takes into account both resource consumption and carbon emissions. Taking the high-performance 
machine-tool product service system as the research object, an implementation architecture of evaluating its carbon emissions was proposed. Three key enabling technologies were presented, that are carbon emissions model in the fabrication phase of industrial products, carbon emissions model in the service phase of industrial products, and carbon footprint network model for service-oriented machining. It is expected that the study can provide a useful reference for achieving low carbon transition in manufacturing.

\section{Acknowledgements}

The research work presented in this paper is supported by the National Natural Science Foundation of China (No. 51605041), and the Innovation Team Funds of the Central Universities, China (No.310825153403).

\section{References}

[1] Li, H., Carbon Emissions Dynamic Characteristics of Mechanical Manufacturing System and Its Carbon Efficiency Assessmemt and Optimization Approach Research in College of Mechanical Engineering of Chongqing University. 2014, Chongqing University: Chongqing, China

[2] Tridech, S. and K. Cheng, Low Carbon Manufacturing: characterisation, theoretical models and implementation. International Journal of Manufacturing Research, 2008. 6(6): 110-121.

[3] Mont, O.K., Clarifying the concept of product-service system. Journal of Cleaner Production, 2002. 10(3): 237-245.

[4] Pandey D, A.M., Pandey J S. , Carbon footprint: current methods of estimation. Environmental monitoring and assessment, 2011. 178(1): 135-160.

[5] Diaz, N., M. Helu, and D. Dornfeld, Design and operation strategies for green machine tool development. Laboratory for Manufacturing \& Sustainability, 2010. 